\title{
Author's Commentary: My Thoughts on Aesthetic Breast Surgery
}

\author{
Toma T. Mugea
}

Aesthetic is the general term for beauty. Beauty is harmony; breast beauty comes from proportions. Breast proportions should fit the patient body.

Connect the patient's desire with the possible surgical achievement. Bring the patient from dreams induced by media to the reality. Life is once and should be respected up to the last day. Do not push the patient for aesthetic surgery if he or she is not decided. Listen to the patient desire and make the relatives' voices softer.

Wait for full breast development before doing a surgical procedure. Inform the patient about the procedure and related risks. Inform the patient about the possible negative results even if rare. Take the full informed consent even for minor surgical procedures. Explain that the surgical result is not forever.

If you want a "stable" result "take a picture." Body shape changes during life, so do breasts. Physiological events like pregnancy always change the breasts. Body weight variation is not recommended if an aesthetic surgery is planned.

Do accurate evaluation and precise chest and breast measurements. Take standard pictures including manubrium, acromion, and umbilicus. Special incidence like "cocktail and beach" view

T.T. Mugea, M.D., Ph.D.

Department of Plastic and Aesthetic Surgery, Oradea

Medical University, Oradea, Romania

Medestet Clinic, 9/7 Cipariu Square,

Cluj-Napoca, Romania

e-mail: drmugea@medestet.ro and supporting breasts are useful in ptotic breast evaluation. Pectoralis muscle contraction can demonstrate the breast animation. Back view may reveal unexpected chest malformation.

Use TTM chart for documenting the case file. Clinical breast examination should be correlated with echography, mammography, and MRI when necessary.

Before starting a surgical procedure, be sure that you know it. You should be able to detect and solve the possible postoperative complications. Ask for seniors' advice when your first thought goes for it. Do not be ashamed to recognize your decisions or results.

Take your time to prepare yourself mentally before the surgery. Never be under stress.

Never hurry. Think calm and be cool in difficult moments. Make notes about the surgery you have done, if particularities happened.

Make your own critics on it and make a file with this. Make suggestions for future similar surgeries. Do not try immediately at home what you saw at the workshop without seeing their results. Do not believe everything exposed in meetings as being "extraordinary."

Pay respect to your teachers. Do respect your colleagues. Be modest. Be fair. Be YOU! 